\title{
A Study on Finite Element Modelling and Analysis with respect to Experimental Results of Strengthened Unreinforced Masonry Walls With and Without Kevlar-FRP
}

\author{
Wijanto, S..$^{*}$, Andriono, T. ${ }^{2}$, and Tanudjaja, J.A. ${ }^{3}$
}

\begin{abstract}
Unreinforced masonry (URM) walls, found in most historical buildings in Indonesia, are relatively brittle with wide variety of material properties. The behaviour of URM walls is very complex, especially when subjected to seismic excitation. In this research, a finite element modelling was set up in order to analyse the seismic performance of URM wall experimental test units, with and without strengthening material. The analysis was conducted using SAP2000 computer program. Three dimensional solids and springs as link connectors were assigned to represent the masonry behaviour. This research aims to compare results obtained from the computer analysis and the previously conducted laboratory experiments. The effectiveness of Kevlar fibre material, which was installed on both wall surfaces and modelled as truss element was also investigated. It was found that the failure mechanisms shown by the SAP2000 model was similar to the laboratory test results. The use of Kevlar Fibre as strengthening material was found able to significantly increase the stiffness and shear capacity of the URM wall.
\end{abstract}

Keywords: Seismic performance; unreinforced masonry; Kevlar Fibre; finite element method.

\section{Introduction}

Masonry is a complex material with a wide range of property values and various characteristics of failure. Various types and quality of two main materials in masonry, which are brick unit and mortar, produce non-constant strength value of masonry in the whole structural model. Complete characteristics of masonry can be determined by laboratory test including compression test and shear test based on codes and regulations. However, there are many difficulties to take into account the properties in whole units of a structure. Therefore, it is common to assume uniform strength distribution of masonry, especially in numerical modelling.

Finite element method (FEM) is a numerical analysis procedure, which is carried out by subdividing the structural model into tens, hundreds, and thousands of elements [1]. Structures with high complexity lead to the complex matrix equation representation that is difficult to be solved.

\footnotetext{
${ }^{1}$ Principal Director PT. Gistama Intisemesta, Л. Puri Kencana Raya Blok J-1/3B, Jakarta 11610, INDONESIA

Lecturer of Civil Engineering Department, Trisakti University, Л. Kyai Tapa No.1, Jakarta

2 Director PT. Gistama Intisemesta, J. Puri Kencana Raya Blok J1/3B, Jakarta 11610, INDONESIA

${ }^{3}$ Structural Engineer PT. Gistama Intisemesta, J. Puri Kencana Raya Blok J-1/3B, Jakarta 11610, INDONESIA

*Corresponding author; Email: s.wijanto1@gistama.com

Note: Discussion is expected before November, $1^{\text {st }} 2021$, and will be published in the "Civil Engineering Dimension", volume 24, number 1, March 2022

Received. 30 March 2021; revised 21 June 2021; accepted 20 July
} 2021
Therefore, the principle of this FEM is to divide a complex structure into small elements which can be described by simple mathematic equations. Wai [2] summarized three types of element, i.e. line (1D), area (2D), and volume (3D) elements. According to the types and various shapes of element that can be modelled, Akin [3] proposed the guideline to determine the effective type of element used in an analysis. A solid element which has three degrees of freedom and six possible stress components is the most suitable choice to be applied in FEM that has high importance in transverse shear deformation.

Miscellaneous elements, such as spring, mass, and rigid link, are supporting elements to represent mechanical modelling of structure. Single link will connect two nodes which are separated in a distance. A tension, compression, and shear strength can be distributed by using this element. Axial, shear and, pure bending can be represented in a link, which should be assigned with either a linear or non-linear property. Figure 1 shows the detail of these elements.

A combination of solid and spring elements can be used to prescribe the cracking failure of components. Liu et al. [5] have discussed about discrete damage zone based on finite element analysis by using spring at interface of solid or continuum element (as shown in Figure 2). In general, every node of the solid element is connected with a spring. However due to its complexity, if the initiated failure location is already known, this location can be preliminarily selected to place these spring elements. 


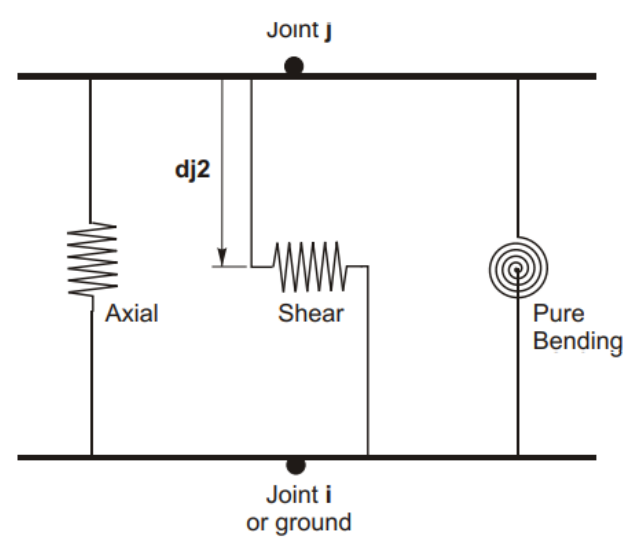

(a)
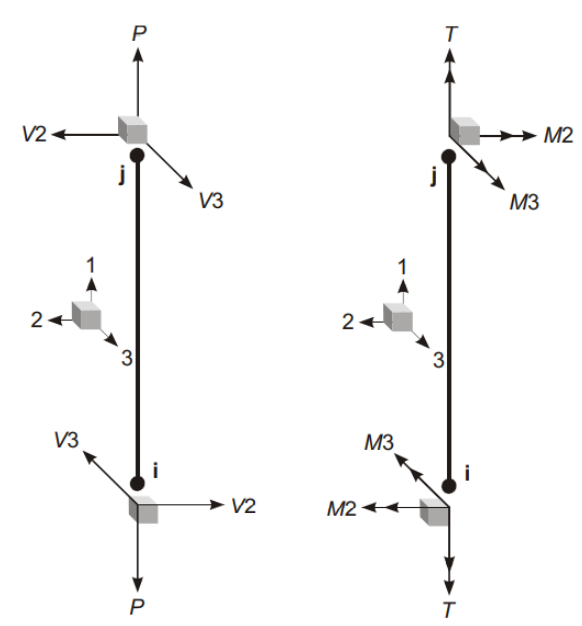

(b)

Figure 1. (a) Spring in a Link Element, (b) Actions of Six Internal Forces and Moments at a Joint (Figures Reprinted from CSI Analysis Reference Manual [4])

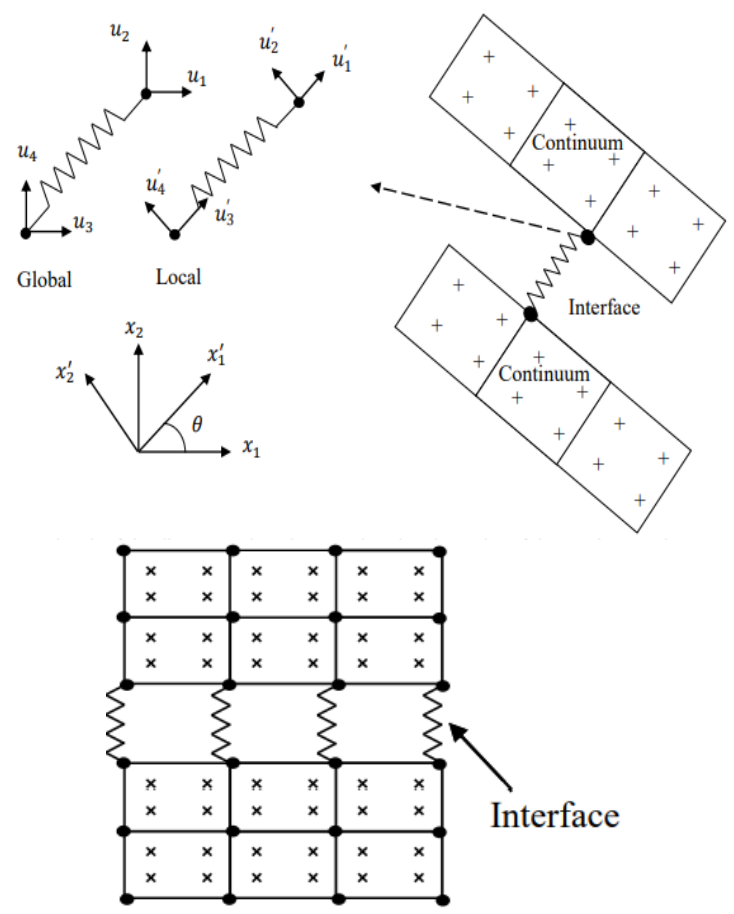

Figure 2. Schematic Diagram Composite Element of Continuum and Spring Element [5]
The intention of this study was to compare the performance of URM-Walls with door opening predicted by the structural analysis using SAP2000 and the results obtained from laboratory test. In this research, a numerical model was set up to simulate the structural behaviour of URM-Walls previously tested in the laboratory [6]. There were two URMWalls to be analysed, URM-Wall with and without strengthening material. The study was focused on the capacity curve and the distribution of solid element stresses through the wall. Another intention of this research was to identify the shear strength enhancement by using a Kevlar fibre as an option in masonry retrofitting.

\section{Modelling URM-Wall in SAP2000}

SAP2000 has been chosen for this project due to its commercial viability in the Indonesian Market. It is one of the integrated software to be used for designing and analyzing engineering structures in 3D-based graphical modelling [4]. Software modelling as the simulation of experimental model was constructed by solid and spring elements. The Test Unit-1 was an URM-Wall with a single door opening at the centre. Concrete block at top and stone foundation at bottom were modelled, including pinned restraints as structural support. Initial compression load, 2.5 MPa at top wall surface was being maintained while lateral load was applied. The structure was meshed into 908 solid elements with 1854 nodes [7]. Each solid finite element has average dimensions of $262.5 \mathrm{~mm}$ (length), $290 \mathrm{~mm}$ (width), and $112.5 \mathrm{~mm}$ (height). Figure 3 shows the URM-Wall Test Unit-1 modelling on SAP2000.

Similar to the SAP modelling of URM-Wall Test Unit1, Test Unit-2 was also modelled in SAP2000 to be investigated and analysed. Test Unit-2 was a Test Unit-1 model, which was strengthened by aramid fibre containing Kevlar material (type AK40). It was applied as truss element in vertical, horizontal, and also diagonal direction on both sides of the wall. Figure 4 shows the modelling of URM-Wall Test Unit 2.

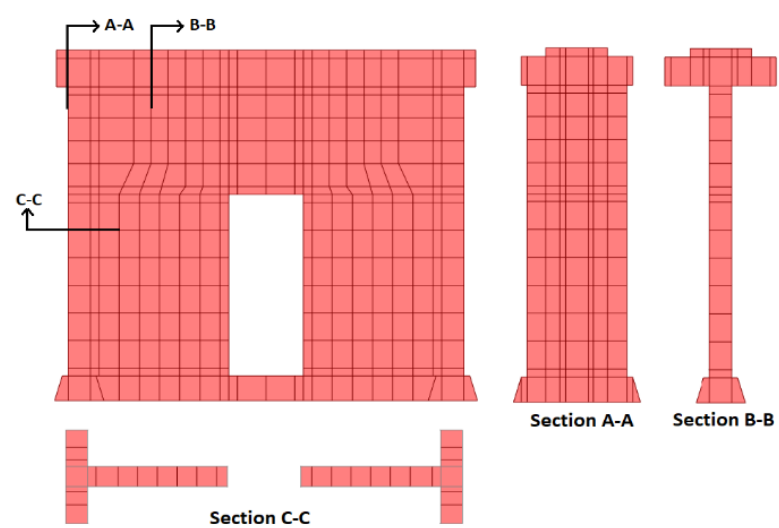

Figure 3. Simple Model of URM-Wall with Single Door Opening (Test Unit-1) on SAP2000 


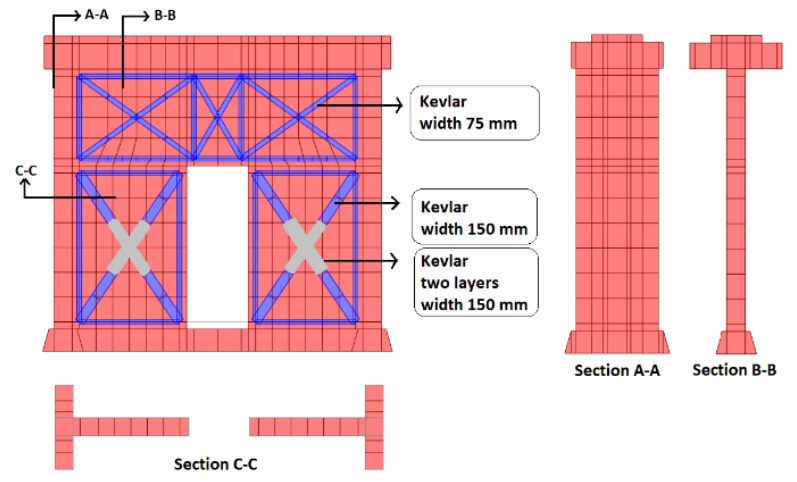

Figure 4. Model of URM-Wall Test Unit 2 on SAP2000

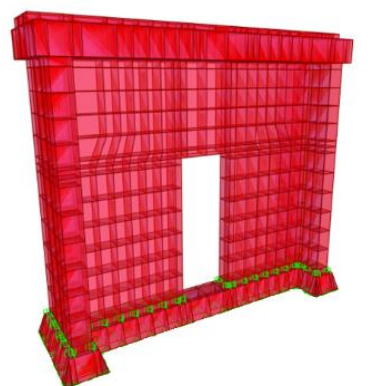

(a)

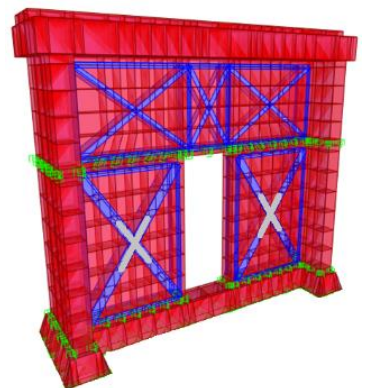

(b)
Figure 5. Link Modelling on (a) Test Unit-1 and (b) Test Unit-2

Spring elements as the link connections were used to describe interactions between the solid elements. To accommodate the occurrence of URM-Wall cracking failure in lateral loading condition, links elements are preliminarily located at bottom of the pier level for Test Unit-1. On the other hand, for Test Unit-2, it was located at top and bottom of the pier. Location selection of the link were observed by location of the opening as the weakness area. Then, it will be reconfirmed by following the high stress pattern in the SAP modeling. Both models are shown in Figure 5.

\section{Defining Material Properties}

The concrete and stone materials as constructed on the model have a compressive strength of $20 \mathrm{MPa}$ and $7 \mathrm{MPa}$, respectively. The material characteristics of URM-Walls used for the analysis of this numerical model were obtained from laboratory testing [6] as homogenized material between bricks and mortar. The material properties as summarized in Table 1 were assigned in SAP2000 structural modelling.

Masonry material was described in non-linear behaviour. It was defined as solid elements on pier, spandrel, and flange's wall components. Compression data for masonry was taken from a prismaticmasonry test (see Figure 6). Tension data, however, was assumed $5 \%$ of the compression strength. Masonry property with stress-strain non-linear curve is shown in Figure 7 with positive in tension.
Table 1. List of Material Properties

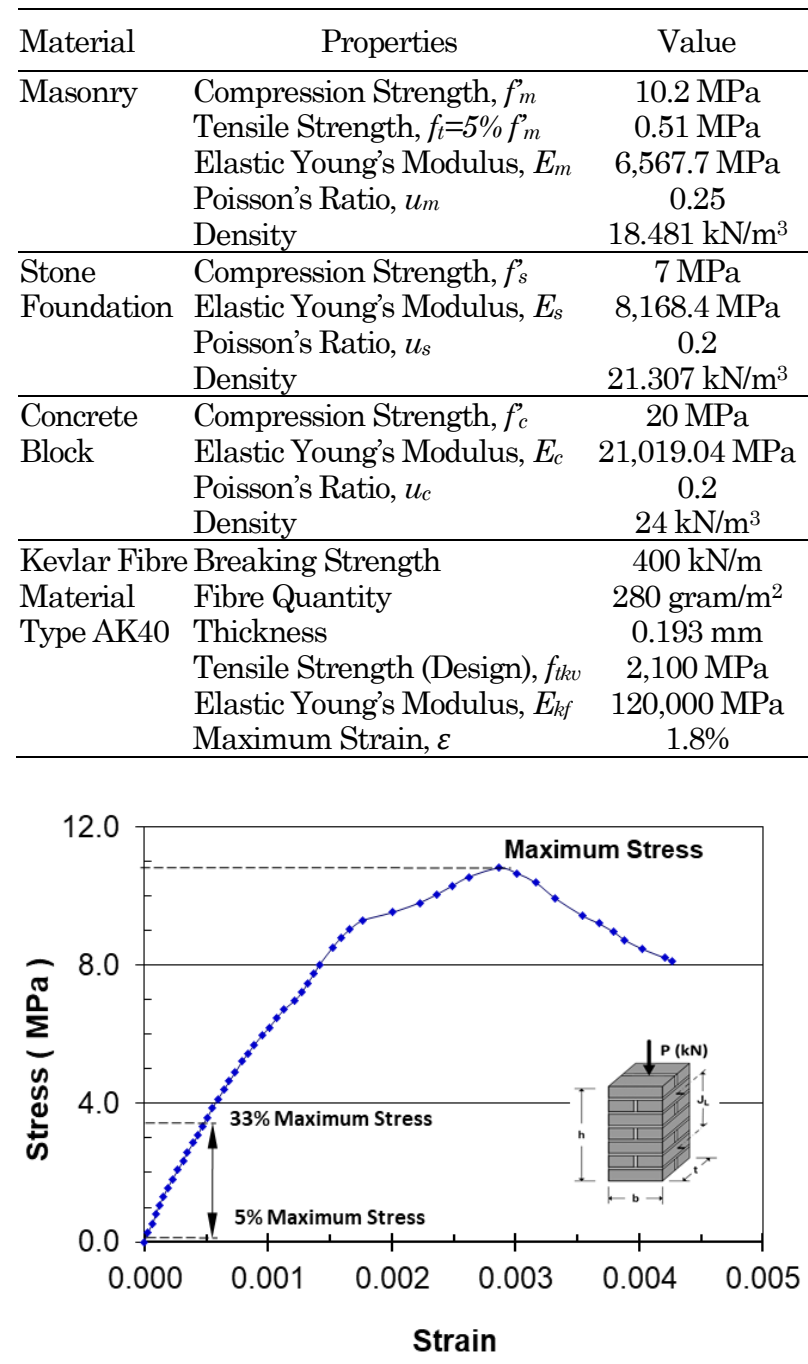

Figure 6. Stress-Strain Curve from the Compressive Strength of Prismatic Masonry [6]

The other material assigned in non-linear curve was Kevlar. Equation 1 shows the breaking strength of Kevlar. This material was designed as truss element to work only in tension. For the connection between Kevlar and brick element, Kevlar was modelled by connecting node points within brick solid element. Property of Kevlar which was assigned in SAP2000 is shown in Figure 8.

$\sigma_{\text {break }}=\frac{400}{0.193}=2,100 \mathrm{~N} / \mathrm{mm}^{2}$

\section{Defining Link Properties}

Two types of link were defined on the model; the first type was in the vertical direction (axial), while the second one was in horizontal direction (shear). Link in the vertical direction represented tension and compression of masonry. Therefore, it followed the non-linear behaviour of masonry material. On the other hand, the horizontal link represented the shear strength of the wall. 


\begin{tabular}{c|c}
\hline Strain & Stress (MPa) \\
\hline-0.00430 & -7.65 \\
-0.00290 & -10.20 \\
-0.00052 & -3.37 \\
0 & 0 \\
0.00008 & 0.51 \\
0.01000 & 0.50 \\
\hline
\end{tabular}

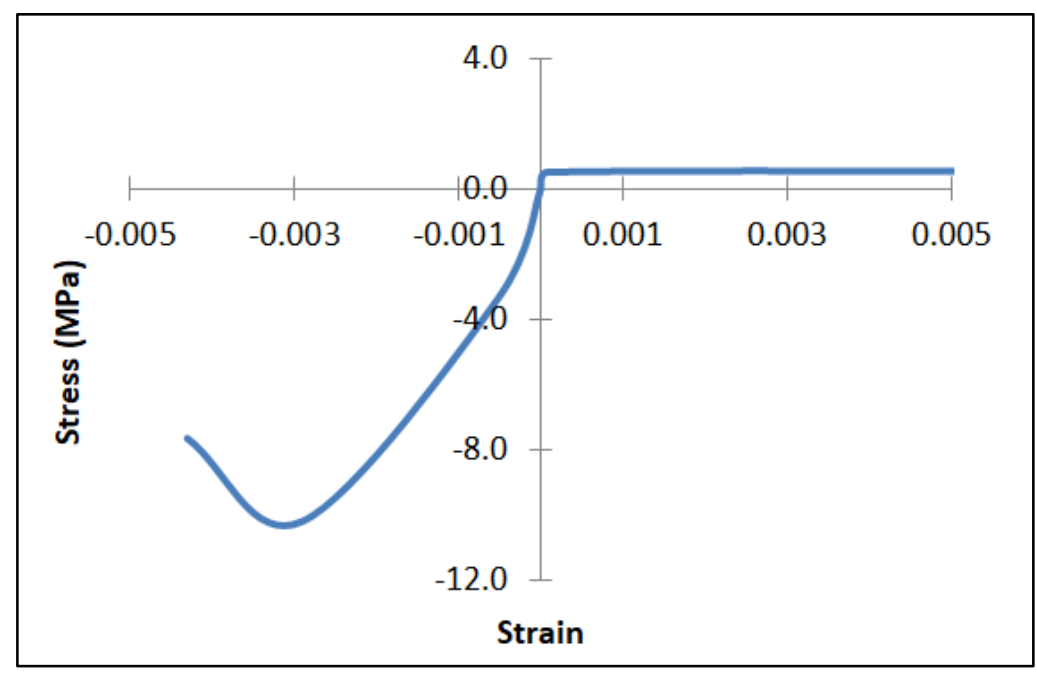

Figure 7. Stress-Strain Curve Data of the Masonry Solid Element

\begin{tabular}{l|l}
\hline Strain & Stress $(\mathrm{MPa})$ \\
\hline-0.0180 & -1 \\
-0.0010 & -1 \\
0 & 0 \\
0.0180 & 2100 \\
0.0185 & 1 \\
\hline
\end{tabular}

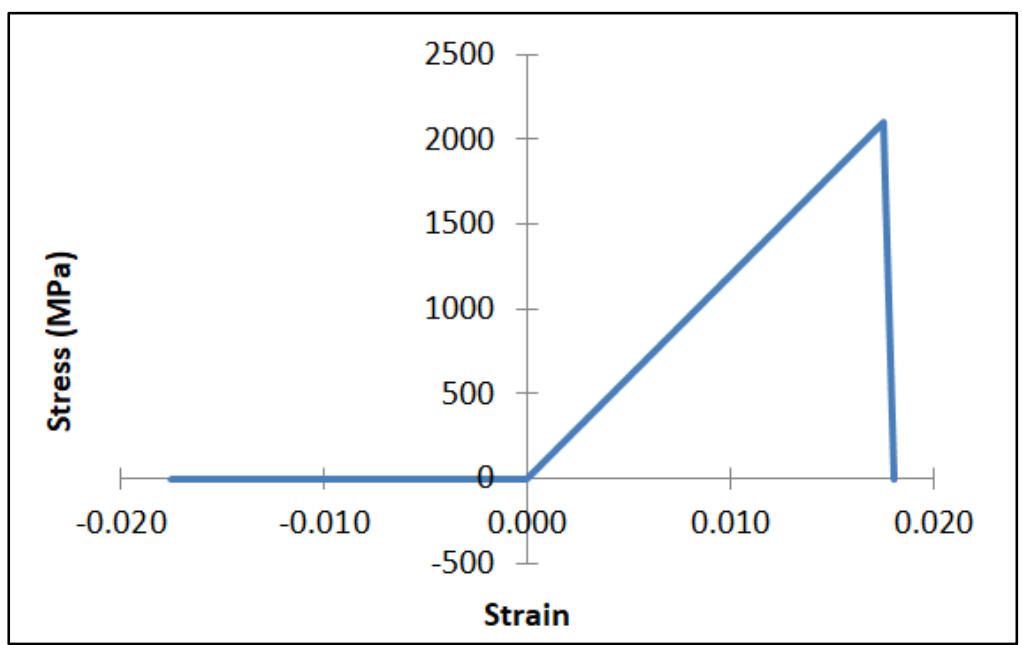

Figure 8. Non-Linear Property Data of Kevlar. Note: Positive in tension

A correlation between shear and elastic modulus in masonry, $G_{m}=0.4 E_{m}$ was suggested in many national codes and literatures, including FEMA 273 [8] and Paulay [9]. They correlate well if compressive loading is predominant. However, it may largely overestimate the stiffness performance due to the cracking anisotropy of the masonry. A huge database of test results has been collected and discussed by Croce et al. [10], and it shows that the average value resulting from the test of shear modulus is as shown in Equation 2:

$G_{m}=0.15 E_{m}$

Therefore, for the definition of link in shear parameter, when there was no crack, the URM-Wall had a shear modulus of 985.16 MPa.

As a crack started to occur, failure in form of initial Bed Joint Sliding due to friction and cohesion ( $\left.V_{B J S 1}\right)$ happened immediately and then continued with final
Bed Joint Sliding due to friction only $\left(V_{B J S 2}\right)$ [11]. The corresponding equations representing the shear strength can be seen in Equations 3, 4, and 5 . Moreover, bed joint sliding strength, $v_{m e}$ was defined by the triplet test result as shown as Figure 9 .

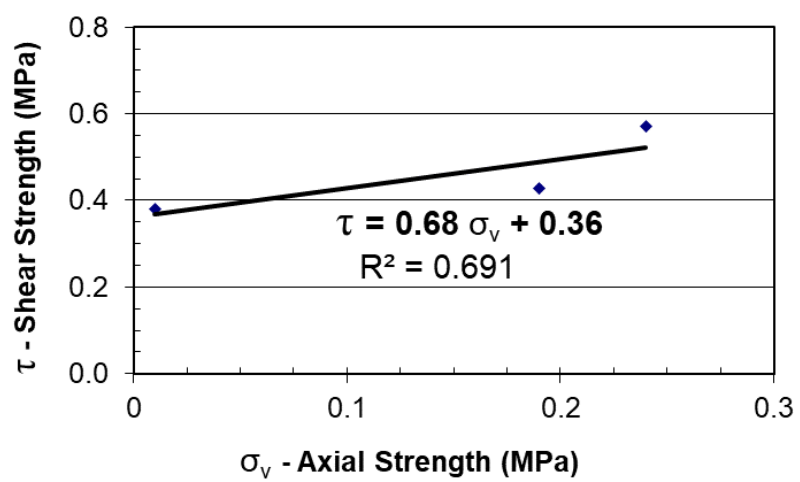

Figure 9. Correlation between Shear Strength vs. Axial Stress based on Laboratory Triplet Test [6] 
$V_{B J S 1}=v_{m e} A_{n}$

$v_{m e}=0.68 \frac{P_{D}}{A_{n}}+0.36$

and,

$V_{B J S 2}=0.68 P_{D}$

Values of $V_{B J S 1}$ and $V_{B J S 2}$ for one pier were $444.716 \mathrm{kN}$ and $226.52 \mathrm{kN}$ respectively of Test Unit-1 model. However, on a link assignment these values have to be generated in the tributary area of one link. As mentioned before, a pier of URM-Wall has dimension of $1800 \mathrm{~mm}$ length x $290 \mathrm{~mm}$ thick, while a solid element has a dimension of $262.5 \mathrm{~mm}$ length $\mathrm{x} 290$ $\mathrm{mm}$ width. Therefore, a pier of URM-Wall was built by single solid element on its thickness, and several solid elements on its length. It is illustrated in Figure 10 that 2 adjacent solid elements have 6 nodes which were assigned with 6 link connections. Therefore, the typical middle link assignments were defined by following Equations 6 and 7.
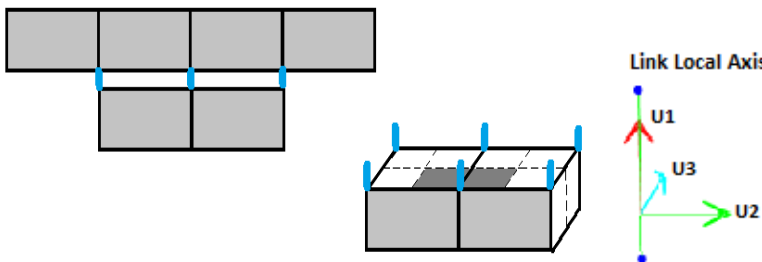

Figure 11. Tributary Area of Single Link Connection

$V_{B J S 1-1 l i n k}=\frac{262.5 \times \frac{290}{2}}{1800 \times 290} \times 444.716 \times 1000=32,427.19 \mathrm{~N}$

$V_{\text {BJS2-1link }}=\frac{262.5 \times \frac{290}{2}}{1800 \times 290} \times 226.52 \times 1000=16,517.07 \mathrm{~N}$

In this research, the locations of links were selected according to the observation on experimental result, representing the weak areas in shear. However, while modelling other types of URM-Wall, these locations should be re-confirmed by the distribution of highest solid stresses calculated by SAP2000. Locations with high solid stresses were predicted for crack occurance

\begin{tabular}{c|c}
\hline Displ $(\mathrm{mm})$ & Force $(\mathrm{N})$ \\
\hline-0.0430 & $-291,178.10$ \\
-0.0290 & $-388,238.00$ \\
-0.0052 & $-128,118.40$ \\
0 & 0 \\
0.0008 & $19,411.88$ \\
0.1000 & $19,023.64$ \\
\hline
\end{tabular}

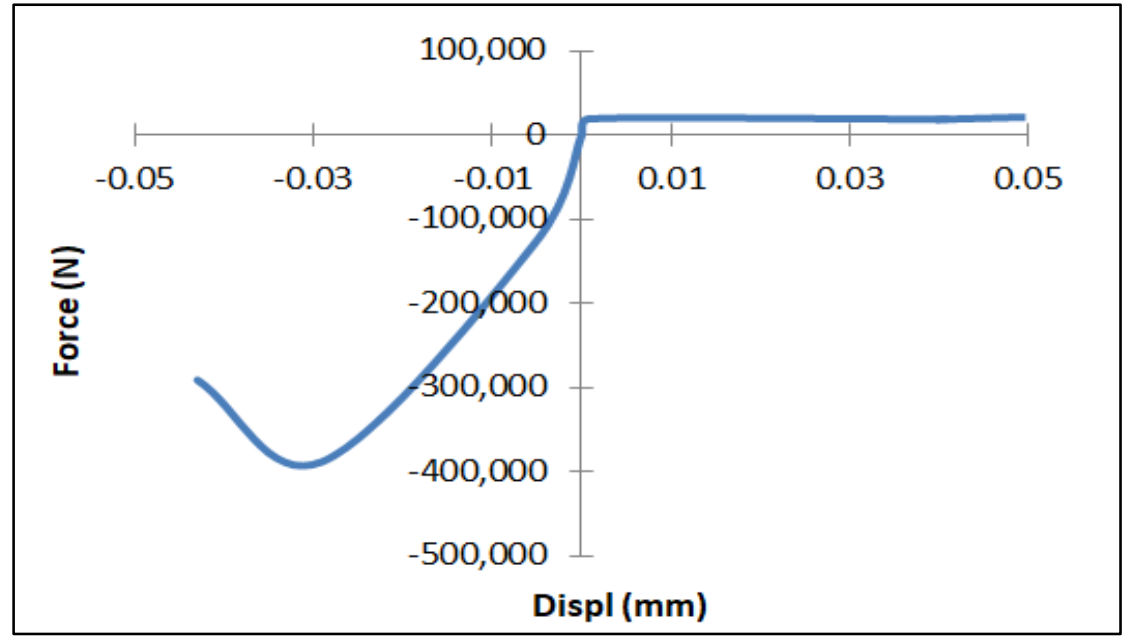

(a)

\begin{tabular}{cc}
\hline Displ $(\mathrm{mm})$ & Force $(\mathrm{N})$ \\
\hline-40 & -0.90 \\
-25 & -1.00 \\
-23 & $-32,427.19$ \\
-21 & $-69,245.53$ \\
-14 & $-69,944.98$ \\
-7 & $-115,420.76$ \\
-0.8 & $-114,277.98$ \\
0 & 0.00 \\
0.8 & $114,277.98$ \\
7 & $115,420.76$ \\
14 & $69,944.98$ \\
21 & $69,245.53$ \\
23 & $32,427.19$ \\
25 & 1.00 \\
40 & 0.90 \\
\hline
\end{tabular}

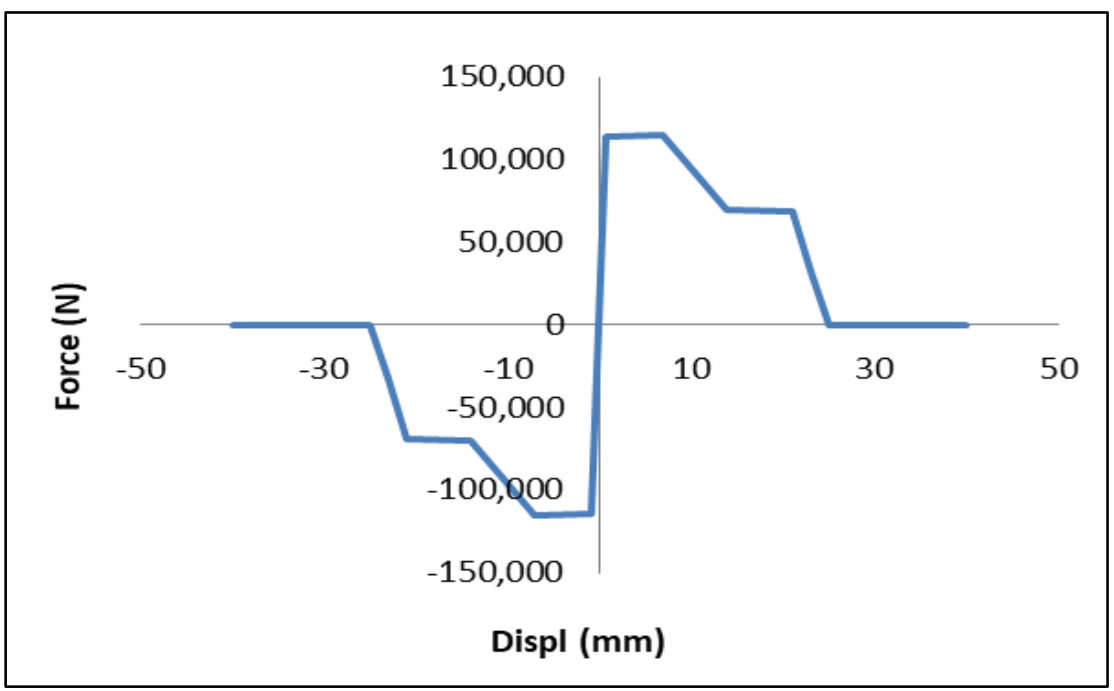

(b)

Figure 10. (a) Link Properties in Vertical, $\mathrm{U}_{1}$ and (b) Horizontal Direction, $\mathrm{U}_{2}$ (Typical for $\mathrm{U}_{3}$ ) 
on the wall. Therefore, location of link model in this research will be an input of further model, which then need to be confirmed from the large stress pattern presentation.

Force-displacement relationship in bed joint sliding action is described in ASCE 41-17 [12], and mirror graph is shown on its different sliding direction. Based on its local axis, link in $U_{1}$ direction means action in vertical direction and $U_{2}, U_{3}$ is in horizontal directions. They were assigned according to masonry's axial and shear strength, as shown in Figure 11(a) and 11(b), respectively. Moreover, the other directions were assigned to be free. Non-linear data for axial and shear link input should be displayed in force and displacement. Therefore, stress-strain on Figure 7, have to be converted based on tributary area of one link element.

On the other hand, Test Unit-2 shows two types of link element in two different levels. The difference between both levels was based on the axial force $\left(P_{D}\right)$ value, which was the superimposed dead load and self-weight above the selected level of link. Therefore, top of the pier will have lower axial force, and impact to the lower shear strength.

Bottom link data has been explained in Equations 6 and 7. And with the same procedure, the top link values of $V_{B J S 1}$ and $V_{B J S 2}$ for one pier were $416.019 \mathrm{kN}$ and $197.823 \mathrm{kN}$. Hence, it was calculated in each link tributary area in Equations 8 and 9,

$$
\begin{aligned}
& V_{\text {BJS1-1link }}=\frac{262.5 \times \frac{290}{2}}{1800 \times 290} \times 416.019 \times 1000=30,335 \mathrm{~N} \\
& V_{\text {BJS2-1link }}=\frac{262.5 \times \frac{290}{2}}{1800 \times 290} \times 197.823 \times 1000=14,424.62 \mathrm{~N}
\end{aligned}
$$

\section{Non-Linear Static Procedure}

The applied loads on the model consist of self-load, initial compression load, and horizontal forces. Loading condition is shown in Figure 12. Pushover analysis that was done on this research was a static non-linear analysis under constant gravity and vertical loads. ASCE 41-17 [12] mentioned combination of gravity load in nonlinear procedures consist of dead load and superimposed dead load, without any scale factors. Gravity loads started first, and then continued by monotonically increasing horizontal load as pushover load case in global $X$ direction. It was done until failure of wall took place. A joint located at top centre of wall, was selected as the control of displacement. Monitored displacement was in $U_{1}$ direction, which was parallel with the horizontal load direction.

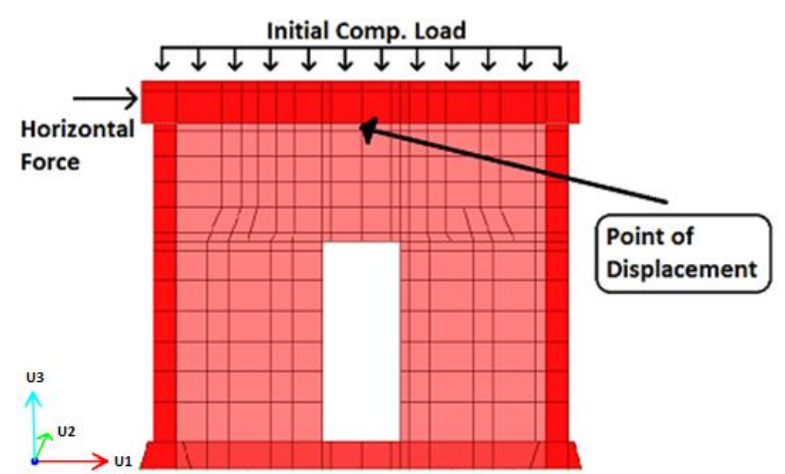

(a)

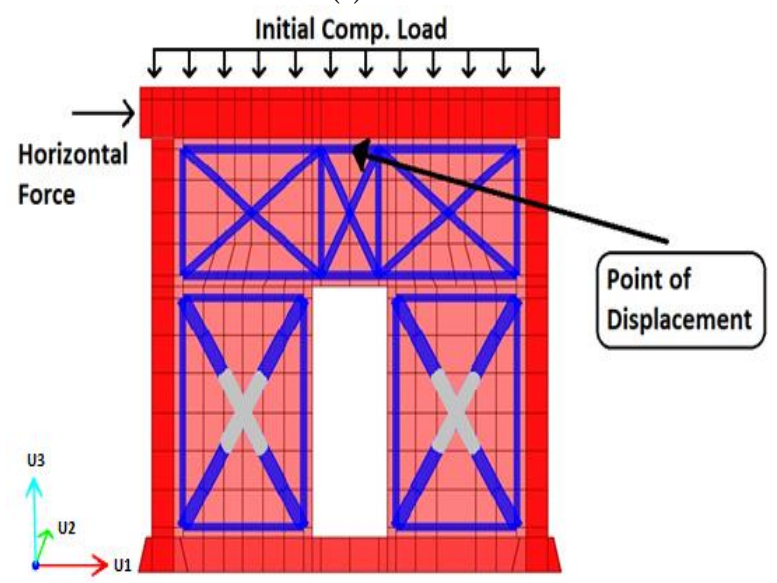

(b)

Figure 12. Detail of Loading Applied on URM-Wall (a) Test Unit-1 and (b) Test Unit-2

\section{Result and Analysis of URM-Wall Test Unit-1}

After all elements and load combination were assigned, the final force-displacement curve of Test Unit-1 was as shown in Figure 13. Test Unit-1 model in SAP2000 reached $456 \mathrm{kN}$ as the maximum force and gradually decreased into $330 \mathrm{kN}$ on $15 \mathrm{~mm}$ of displacement.

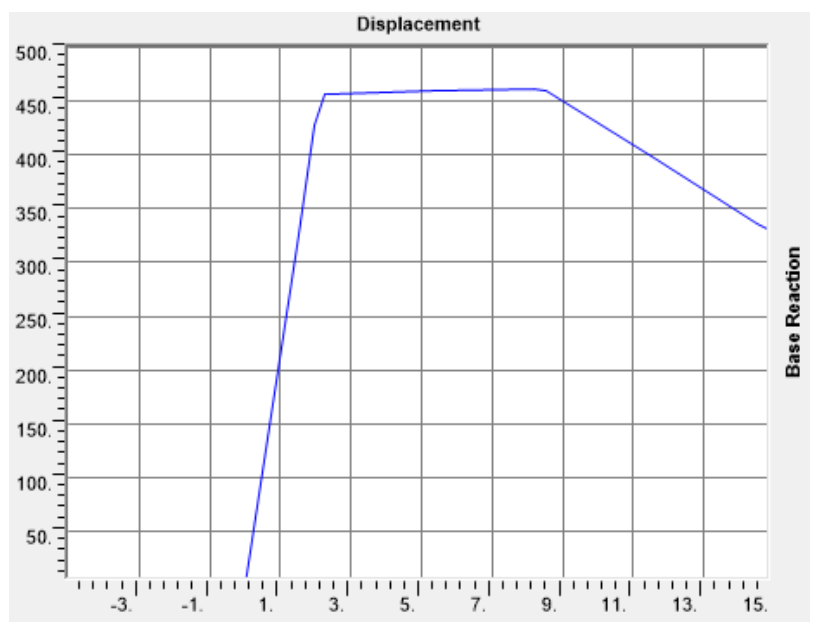

Figure 13. Capacity Curve on SAP2000 (kN, mm) 
Laboratory test result for URM-Wall Test Unit 1 is shown in Figure 14(a). However, cyclic loading on laboratory test carried out exactly the actual measurement in every cycle. Therefore, maximum forces on each cycle were collected and idealized to be compared with the computer analysis result (see Figure 14(b)). This idealized curve produced the maximum force, which was about $416 \mathrm{kN}$ in $8 \mathrm{~mm}$ displacement. It was found that the software model approach showed that the URM-Wall strength was $9.6 \%$ higher than the experimental model in laboratory.

Figure 15 represents analysis results of maximum tension and compression stresses, representing $S_{11}$ stresses in SAP2000. Critical areas in tension figured in blue colour of $0.7 \mathrm{MPa}$ was located at the left top corner of door opening and left bottom of pier. On the other hand, maximum compression stresses presented in red colour were shown at right section of the structure.

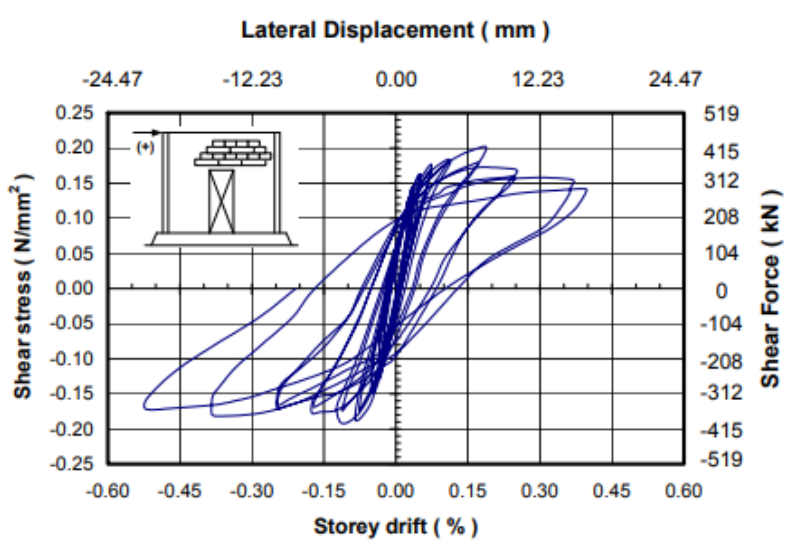

(a)

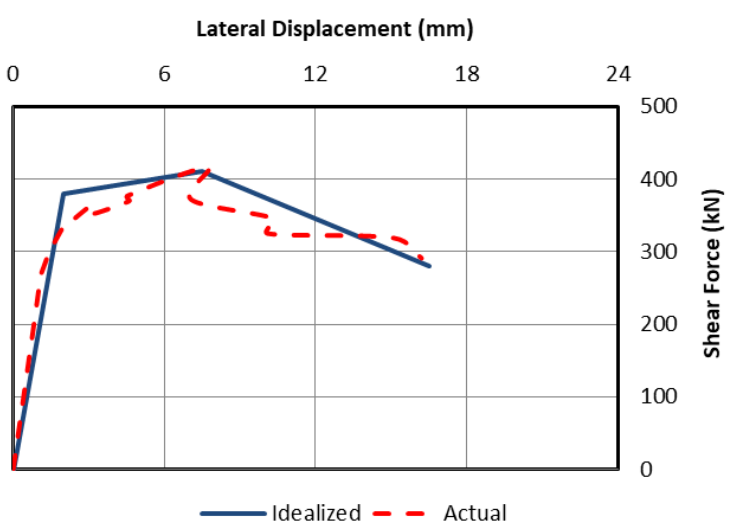

(b)

Figure 14. (a) Capacity Curve of Test Unit-1 Laboratory Test and (b) Idealized Curve based on ASCE 41-17 [12], Figure 7-3

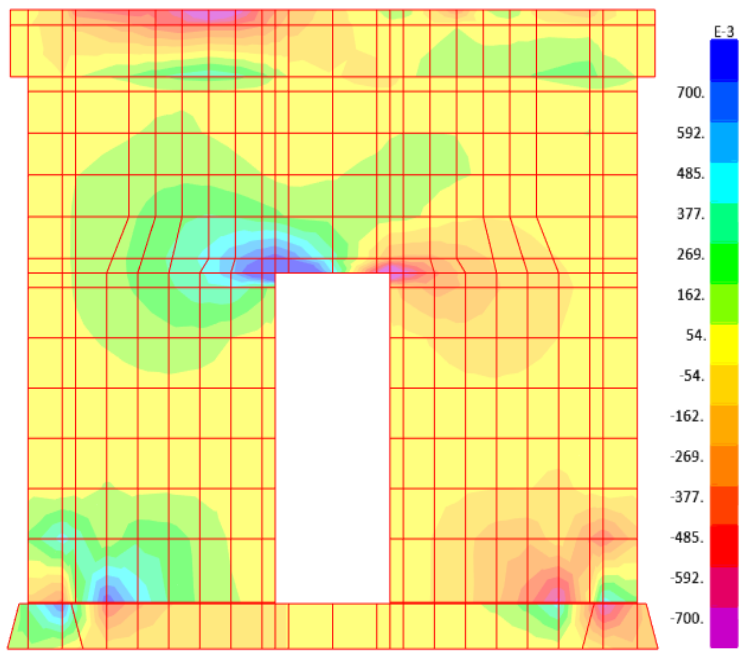

(a)

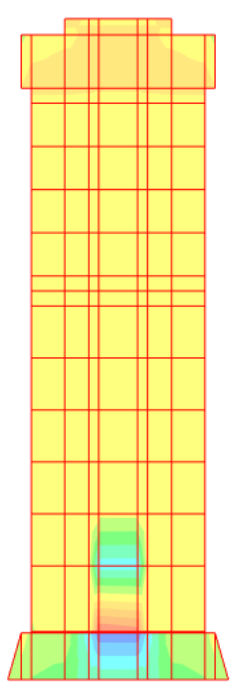

(b)

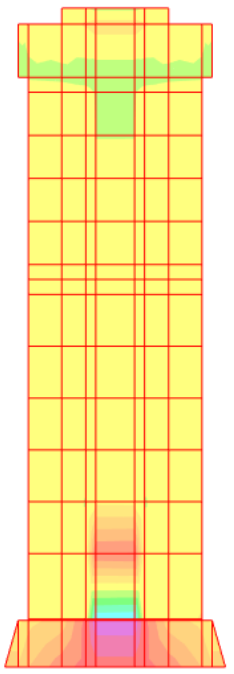

(c)

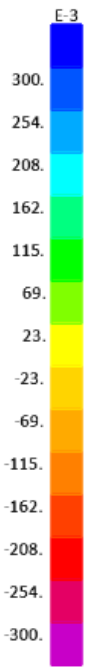

Figure 15. Solid Stresses $\left(S_{11}\right)$ Test Unit-1 in (a) Horizontal Section, (b) Left, and (c) Right Section. Note: Positive means tension and negative means compression.

The shear stresses acting on the URM-Wall were followed by $S_{12}$. Location of high shear stresses occuring in wall, then need to be verified with the location of link modeling. As can be seen in Figure 16, concentration of highest shear stresses occured at the bottom level of pier that presented in blue colour. Therefore, it was confirmed that link properties should be modelled at this level.

Combination between high stresses in tension, compression, and shear occurred to establish potential cracking area on the wall. Furthermore, small cracks indicated to become line cracking on both pier sections in experimental test, as shown in Figure 17. 


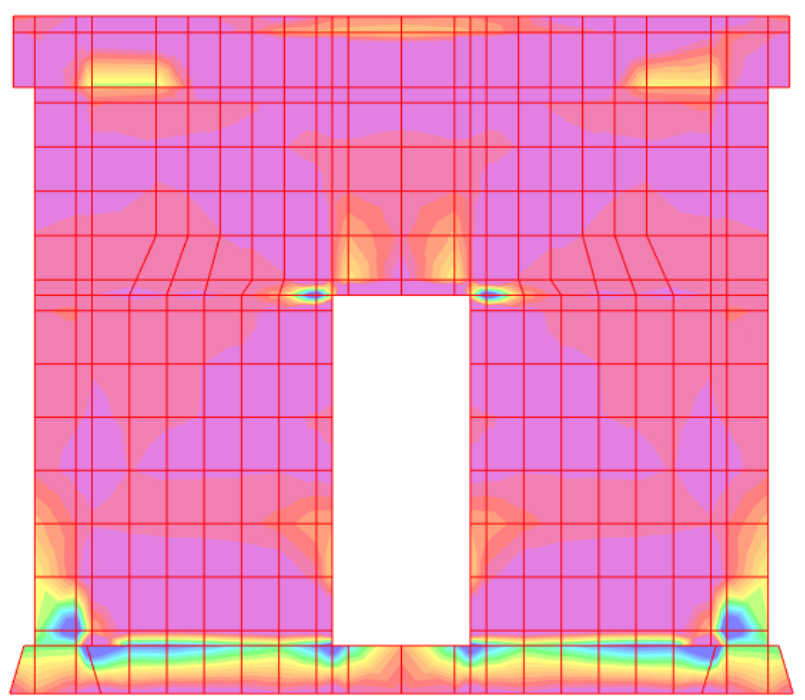

(a)

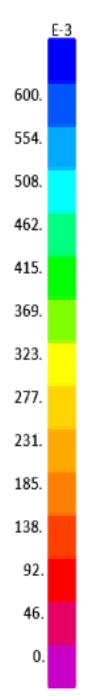

Figure 16. Solid Stresses $\left(S_{12}\right)$ Test Unit-1 in (a) Horizontal Section, (b) Left, and (c) Right Section

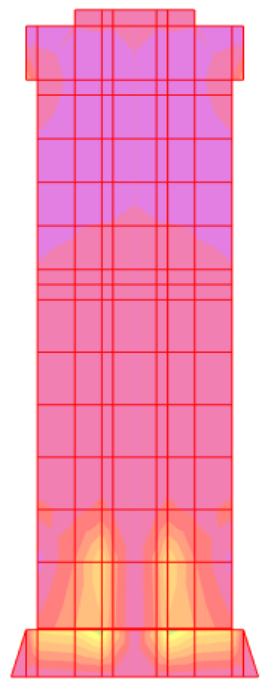

(b)
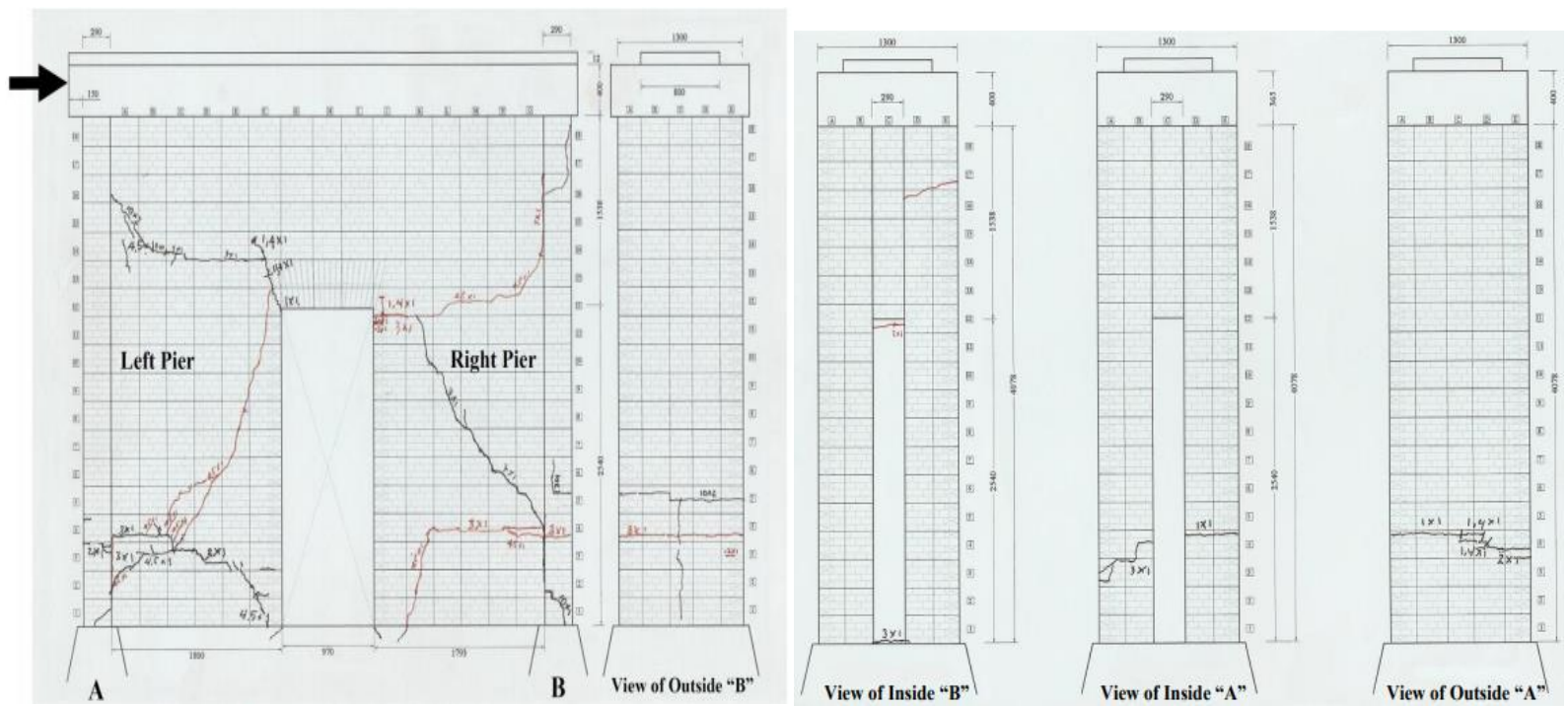

Figure 17. Crack Pattern of Test Unit-1 on Laboratory Test. Note: Black colour means cracking by left side load, red colour means cracking by right side load.

\section{Result and Analysis of URM-Wall Test Unit-2}

SAP2000 Model URM-Wall with Kevlar provided capacity curve, as presented in Figure 18(a). There was a non-straight curve with the maximum force of $612 \mathrm{kN}$. The force that could be resisted by URM-Wall with Kevlar performed higher than URM-Wall without any strengthened material. The experimental laboratory model had a capacity curve, as shown in Figure 18(b). The maximum force that could be reached in URM-Wall Test Unit-2 was $536 \mathrm{kN}$. Therefore, it was found that the maximum force of SAP2000 model was $14.2 \%$ higher than the laboratory test record.

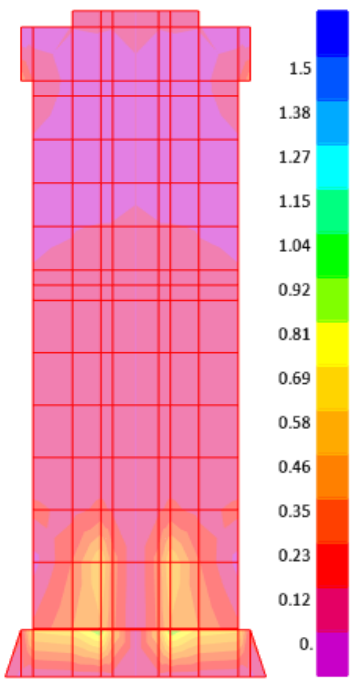

(c)

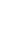




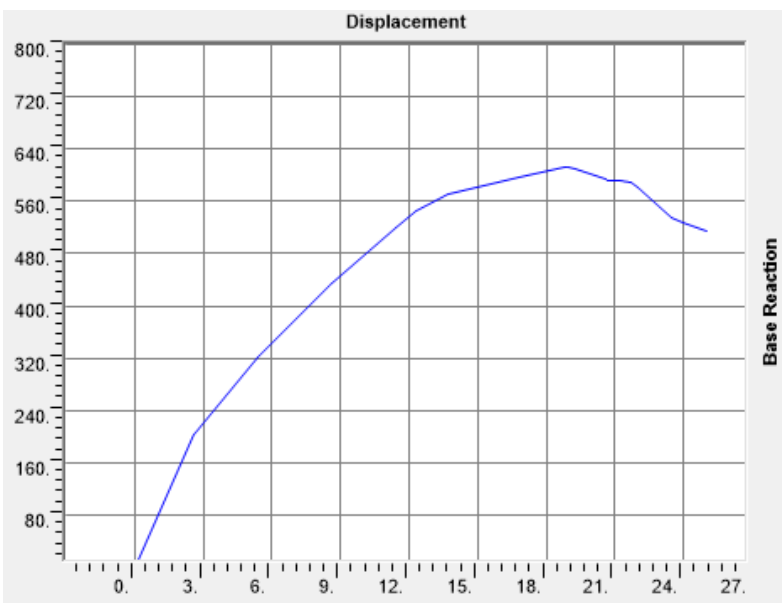

(a)

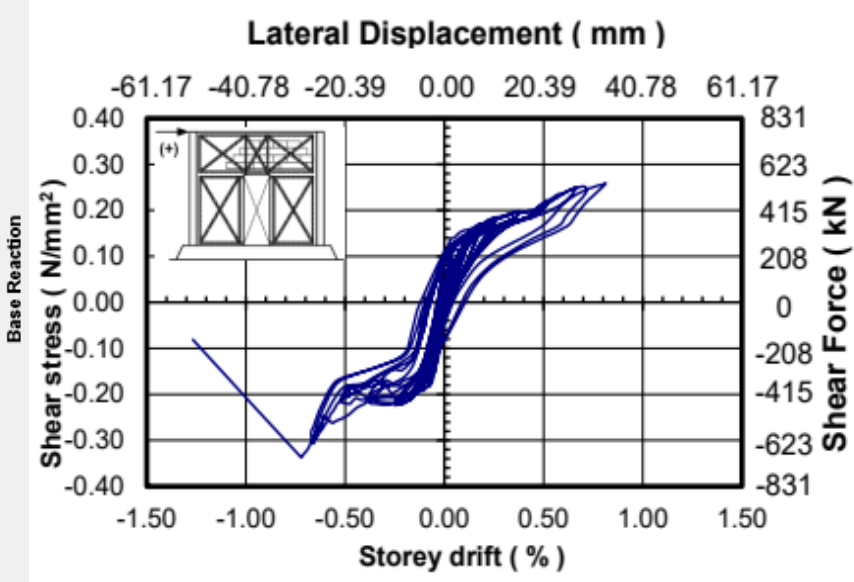

(b)

Figure 18. Capacity Curve of Test Unit-2 (a) on SAP2000 (kN, mm) and (b) Laboratory Test

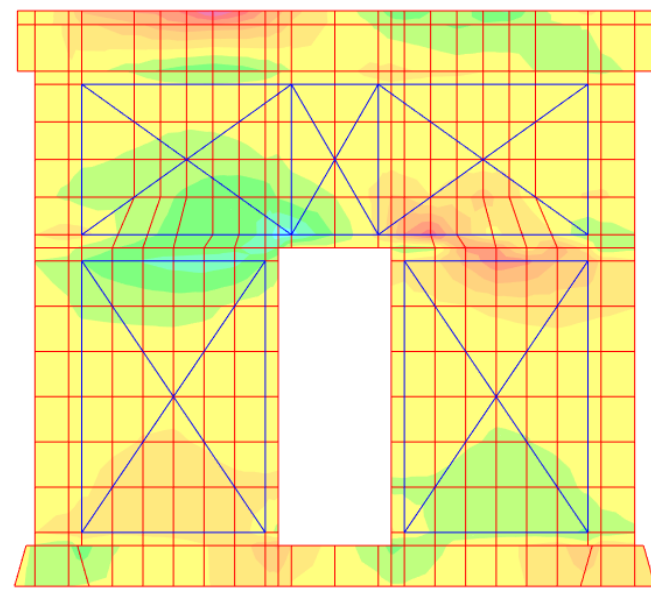

(a)

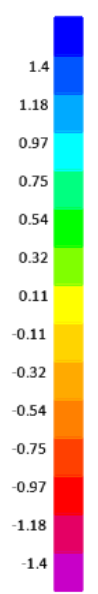

Figure 19. Solid Stresses $\left(S_{11}\right)$ Test Unit-2 in (a) Horizontal Section, (b) Left, and (c) Note: Positive means tension and negative means compression.

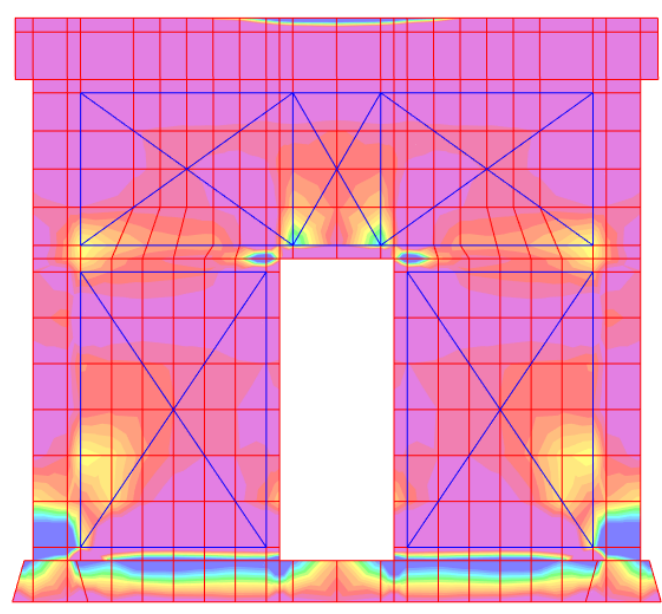

(a)

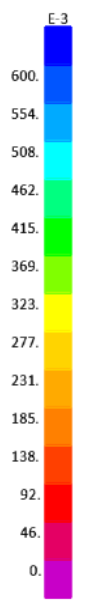

Figure 20. Solid Stresses $\left(S_{12}\right)$ Test Unit-2 in (a) Horizontal Section, (b) Left, and (c) Right Section of URM-Wall with Kevlar

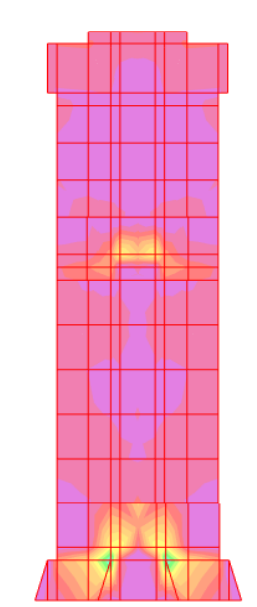

(b)

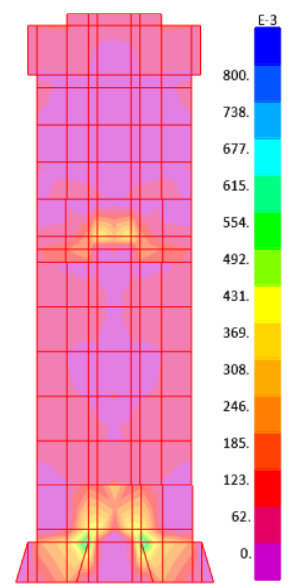

(c)
Compared to the cracks observed in the experimental model as shown in Figure 21, line cracks occurred horizontally at top and bottom level of opening, moreover diagonal cracking were shown through the

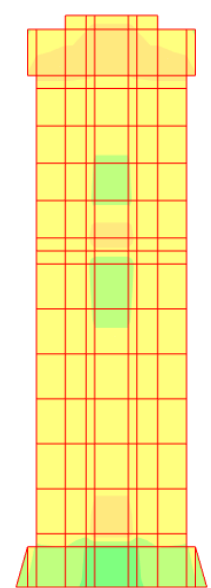

(b)

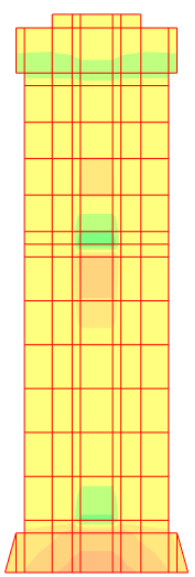

(c)

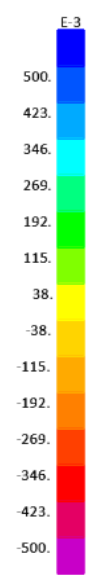

piers. Therefore, it is confirmed that the pattern of high solid stresses including tension-compression and shear can represent the failures occurred in the wall. 

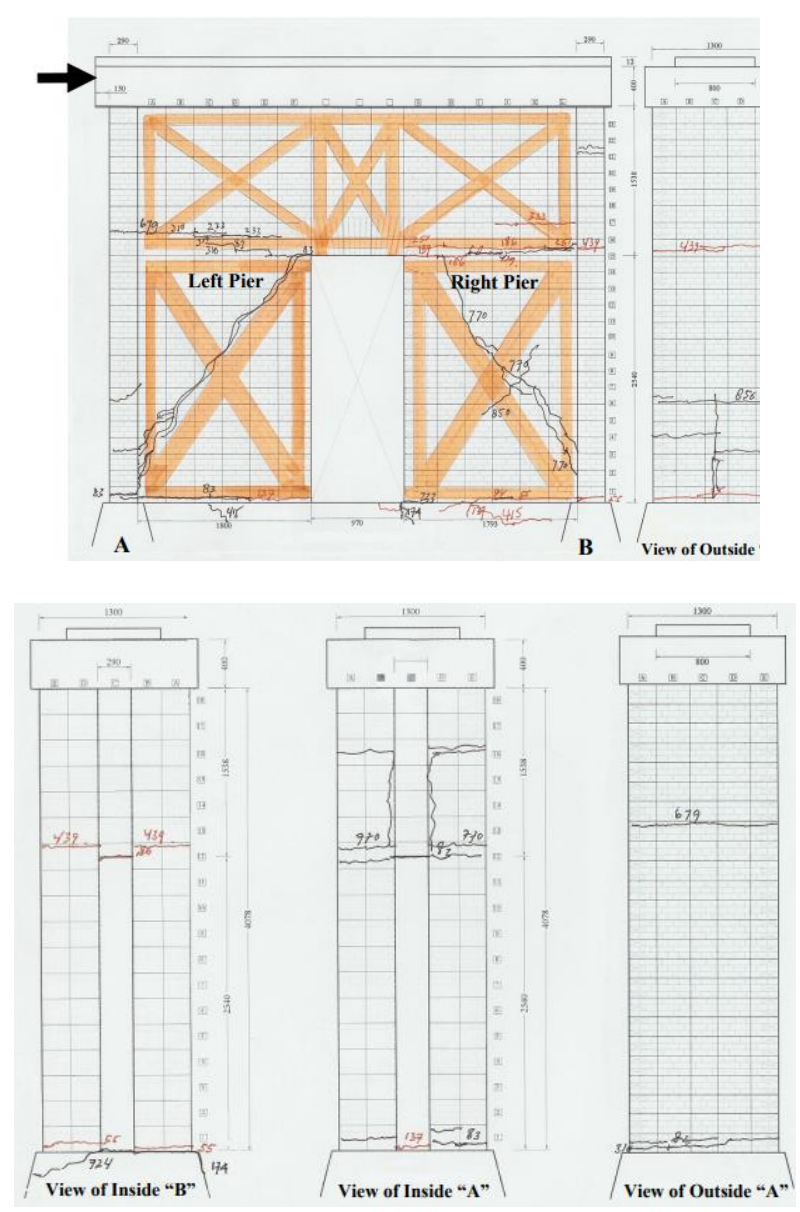

Figure 21. Crack Pattern of Test Unit-2 on Laboratory Test. Note: Black colour means cracking by left side load, red colour means cracking by right side load.

The ultimate strength that was reached in capacity curve of both models was higher, with no more than $15 \%$, than data of force and displacement from the laboratory experiments. It was performed by the anisotropy material of masonry in particular on the homogenity and integrity of the wall. Therefore, a correction factor value should be proposed in masonry design parameter to cover this overestimated masonry strength.

\section{Conclusions}

This research project aims to compare the results obtained from the computer analysis with previously conducted experimental results. The comparison found that the analysis results showed similar stress distributions and capacity curves which were obtained from the laboratory experiments. In particular, large stresses shown on the software model were in line with the typical cracks and failure on the experimental Test-Units.

Both the computer analysis and experimental results had found that the URM-Wall Test-Unit with Kevlar fibre, applied in the diagonal directions of both wall surfaces, caused a significant increase in stiffness and shear capacity compared to the URM-Wall Test-Unit without Kevlar. This further validates the previous experimental results that Kevlar materials could be used to strengthen the URM-Wall strength to resist high lateral inertia seismic loads.

Although the research project concludes that FEM in SAP2000 can simulate the behaviour of unreinforced masonry structures, there are certain limitations, which cannot be addressed in this research project. Notably, the behaviour of wall cracking, that will open and close during lateral cyclic loadings, could not be fully simulated in SAP2000. Moreover, the shear modulus in solid elements would automatically be calculated as 0.4 times the modulus of elasticity in the program. This value may not be appropriate as masonry might have lower shear strengths when the cracks occurred. According to this study, it can be concluded that the application of link modeling was useful as an approach method in URM-Wall modeling.

A better approach and more appropriate modification of the computer modelling should be considered for future research. In addition, future research should extend comparison of computer analysis and experimental results to other types of wall and strengthening material, to validate the use of Finite Element Method.

\section{References}

1. Malkus, D.S. and Cook, R.D., Concepts and Applications of Finite Element Analysis, $4^{\text {th }}$ edition, John Wiley \& Sons, Inc, 2001.

2. Wai, C.M., Rivai, A., and Bapokutty, O., Modeling Optimization Involving Different Types of Elements in Finite Element Analysis, $2^{\text {nd }}$ International Conference on Mechanical Engineering Research (ICMER), Institute of Physics Publishing, 50, 2013.

3. Akin, J.E., Finite Element Analysis Concepts via SolidWorks, World Scientific Publishing Co. Pte. Ltd., Singapore, 2009.

4. Computers \& Structures, Inc., CSI Analysis Reference Manual for SAP2000, ETABS, SAFE and CsiBridge, United Sates of America, 2017.

5. Liu, X., Duddu, R., and Waisman, H., Delamination Analysis of Composites Using a Finite Element Based Discrete Damage Zone Model, International Conference, Society for the Advancement of Materials and Process Engineering (SAMPE), Baltimore, MD, 2012.

6. Wijanto, S., Andriono, T., and Tanudjaja, J.A., Seismic Behaviour of Strengthened Unreinforced Masonry Walls using Kevlar-FRP, Civil Engineering Dimension, , 23(1), 2021, pp. 44-53. 
7. Wijanto, L.S., Seismic Assessment of Unreinforced Masonry Walls, PhD thesis, Department of Civil Engineering, University of Canterbury, New Zealand, 2007, p.188.

8. FEMA 273, NEHRP Guidelines for the Seismic Rehabilitation of Buildings, Federal Emergency Management Agency, Washington, D.C., 1997.

9. Paulay, T. and Priestley, M. J. N., Seismic Design of Reinforced Concrete and Masonry Buildings, John Wiley \& Sons, Inc, 1992.
10. Croce, P. et al., Shear Modulus of Masonry Walls: A Critical Review, XIV International Conference on Building Pathology and Construction Repair CINPAR, Procedia Structural Integrity, 11, 2018, pp. 339-346.

11. FEMA 306, Evaluation of Earthquake Damage Concrete and Masonry Wall Buildings, Federal Emergency Management Agency, Washington, D.C., 1998.

12. ASCE/SEI 41-17, Seismic Evaluation and Retrofit of Existing Buildings, American Society of Civil Engineers, Reston, VA, 2017. 